\title{
EXPERIMENTAL VERIFICATION OF THE AXIAL AND LATERAL STIFFNESS OF LARGE W7-X RECTANGULAR BELLOWS
}

\author{
J. Reich $^{1)}$, A. Cardella ${ }^{1)}$, A. Capriccioli' ${ }^{2}$, T. Koppe ${ }^{1)}$, B. Missal ${ }^{1)}$, \\ W. Löhrer ${ }^{3)}$, S. Langone ${ }^{4)}$, P.-C. Sassone ${ }^{5)}$ \\ 1) Max-Planck-Institut für Plasmaphysik, EURATOM Association, Wendelsteinstraße 1, \\ $D-17491$ Greifswald Germany \\ 2) ENEA, Via Enrico Fermi 45, I-00044 Frascati \\ 3) Kompaflex AG, Amriswiler Straße 92, $\mathrm{CH}-9314$ Steinebrunn \\ 4) Romabau-Gerinox AG, Fohlenweide, $\mathrm{CH}-8570$ Weinfelden \\ 5) Idrosapiens S.r.I., Strada Volpiano 49, I-10040 Leini
}

\begin{abstract}
The WENDELSTEIN 7-X (W7-X) is a super-conducting helical advanced stellarator. W7-X is provided with 299 ports, which connect the plasma vessel with the outer vessel. All the ports are equipped with bellows, which, during bake-out and final adjustment, compensate the relative movements of the vessels.

The lateral stiffness which was calculated with the established standard EJMA-code [1] seemed to be relatively small. This appeared to be not correct in particular for non circular bellows. The stiffness of rectangular, multi-layer bellows have then been re-calculated with the Finite Element Method (FEM) code ANSYS.

The maximum difference between the FEM and EJMA code resulted to be up to $250 \%$ in particular with movements along the longer side of the bellows.

In order to clarify the differences a test-campaign with the largest rectangular bellows was performed.

The paper summarises the calculation, describes the test activities, the apparatus and reports the final results.
\end{abstract}

\section{Introduction}

WENDELSTEIN 7-X (W7-X) is a stellarator device which is presently under construction at the Max-Planck Institut für Plasmaphysik (IPP) in Greifswald, Germany.

Plasma vessel and outer vessel are connected by ports. In total 299 ports provide access to the plasma from outside to the plasma vessel. The ports are distributed around the torus.

Each port is equipped with bellows which compensate for movements of the plasma vessel relative to the outer vessel. The movements occur during bake-out at $150^{\circ} \mathrm{C}$ or cooling down to room temperature or during fine adjustments.

The bellows work in a similar way as a spring. However the behaviour of multilayer bellows is not linearly elastic. Bellows have their own spring rate. Any displacements 
against these bellows result in spring forces which are resisted by the support system of the vessels. The design of the support system is strongly influenced by the sum of all spring forces.

All spring rates of the manufactured bellows were calculated by the supplier. At an inspection the already produced bellows were checked. Evidently they seemed to be quit stiffer in both lateral directions with respect to the axial direction. It was then decided to recalculate the spring rate by the FEM-method.

The results of this recalculation showed significant differences between the given spring rate values from the supplier and the recalculated values.

In order to clarify these differences it was decided to perform a test on a prototype of the rectangular bellows.

\section{Ports and bellows}

The ports as the connection between the plasma and the outer vessels were designed in two different forms for diagnostics and for supply lines. To meet the requirements of the various users the bellows of the diagnostic ports are situated inside the port tube, whereas the bellows in the ports for the supply lines are located outside [2].

According to the shape of the ports the design of the bellows varies from round over oval to rectangular shape.

Round bellows consist of just one layer of stainless steel with a wall thickness of 0.5 $\mathrm{mm}$. Oval and rectangular bellows are designed to have three layers, each of $0.4 \mathrm{~mm}$ wall thickness (Fig.1). The middle layer is perforated for gas exchange. 


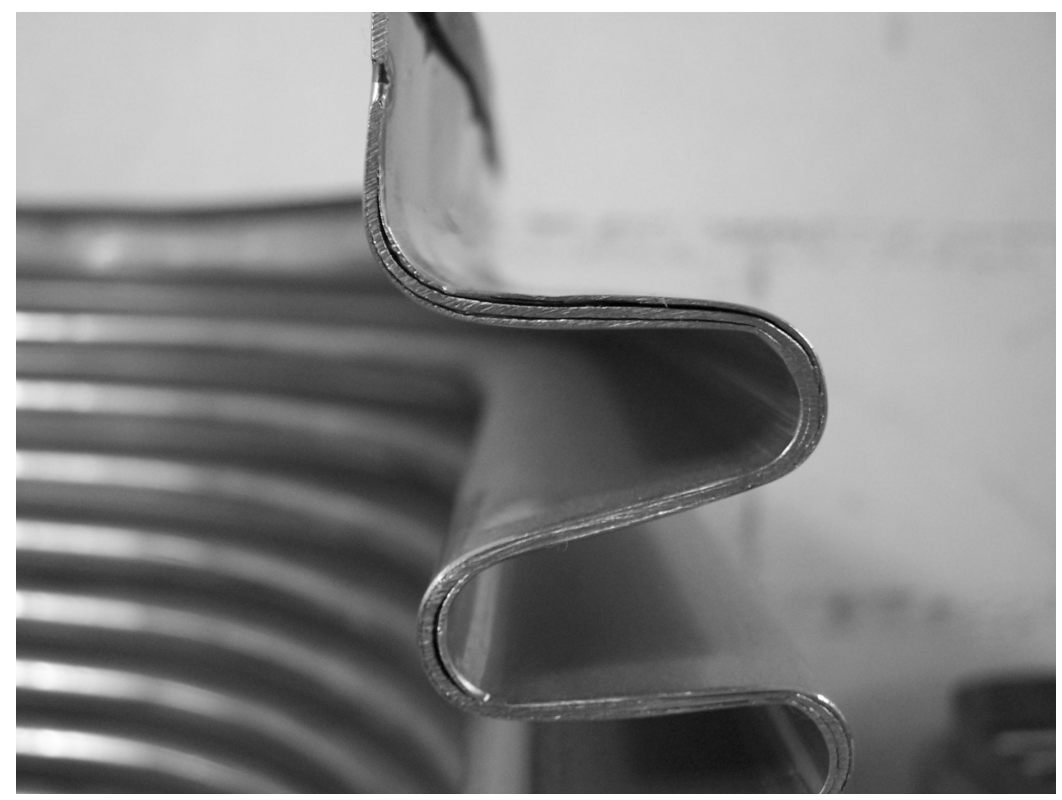

Fig. 1. Cut of three layers, rectangular bellows

During the operation time it is foreseen to perform a vacuum between the layers of the bellows which will make them stiffer and avoid the destruction of single layers. Like the ports the bellows are also made of the austenitic steel DIN 1.4429.

\section{Calculation of bellows spring rate}

In general all bellows will be calculated by the manufacturer according to the EJMA code. This code is well proved for circular bellows. The used formulas are based on statistics which were determined by testing of various shapes.

For the design of oval and rectangular bellows the EJMA code only recommends formulas. There are a few uncertainties in calculation especially within the region were long sides turn into curves of the bellows.

Normally the customers do not need the spring rate in detail; this means it is not necessary to approve the calculated values by test series.

Usually tolerances of the produced spring rates vary within $\pm 10 \%$. These tolerances derive from factors like the technology of the manufacturing process, material, thickness of the material, etc. 
For confirmation of the EJMA code values an additional calculation was initiated. Therefore the Finite Element Method (FEM) was used.

The largest rectangular bellows $(1170 \times 570 \mathrm{~mm})$ were exactly modelled in real dimensions including the three layers. A view of the rectangular FE model is shown in fig. 2 [3].

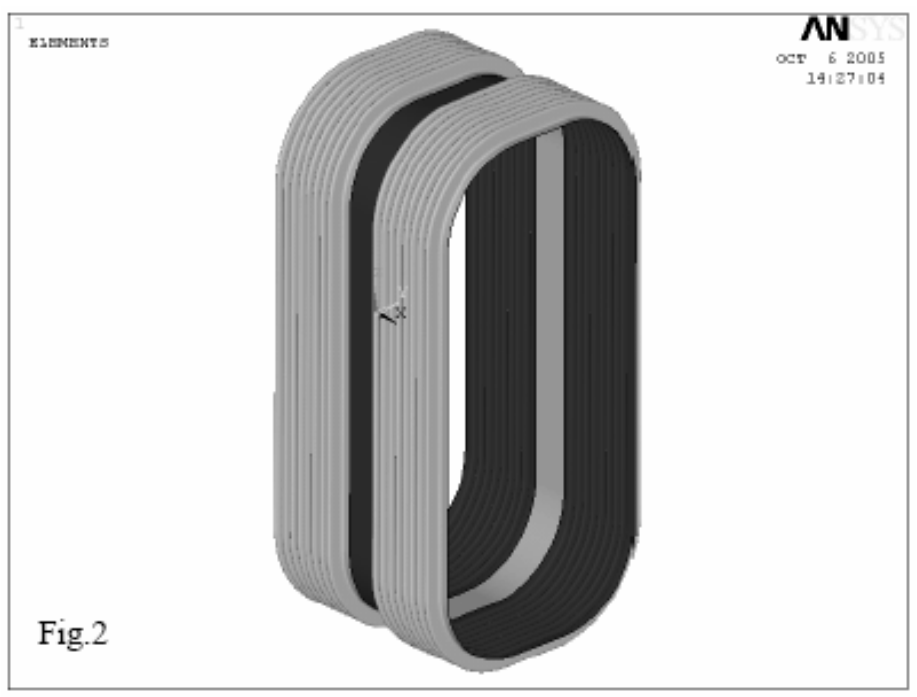

Fig. 2. Rectangular bellows modelled in FEM ANSYS

For calculation all nodes were fixed on one side (base $\mathrm{x}=0$ ). For determination of the axial stiffness all nodes on the opposite side were able to perform axial displacements. The same definition was given for calculation of lateral stiffness (over long and short side of the bellows). Here all nodes were able to move in lateral directions. 
In table 1 the results of both, the theoretical values according to the EJMA code and the FEM-calculation, are reported. Discrepancies up to $250 \%$ in lateral direction were identified.

\begin{tabular}{|c|c|c|c|}
\hline & $\begin{array}{c}\text { Axial spring-rates } \\
{[\mathrm{N} / \mathrm{mm}]}\end{array}$ & $\begin{array}{c}\text { Lateral spring-rates } \\
\text { long side }[\mathrm{N} / \mathrm{mm}]\end{array}$ & $\begin{array}{c}\text { Lateral spring-rates } \\
\text { short side }[\mathrm{N} / \mathrm{mm}]\end{array}$ \\
\hline EJMA code & 59 & 193 & 42 \\
\hline FEM calculation & 64 & 474 & 147 \\
\hline Deviation & $8 \%$ & $146 \%$ & $250 \%$ \\
\hline
\end{tabular}

Table 1. Comparison of spring-rate values

In conclusion to these results it was decided to develop a test-equipment for the largest rectangular bellows to determine the axial and lateral spring rates.

\section{Test apparatus for rectangular bellows}

By designing the test apparatus it had to be considered that the spring rates have to be measured in axial direction and over the long and short side of the bellows (figures 3 and 4). The friction between the moveable parts of the apparatus was minimised in order to avoid errors in the results.

The permanent movements of the bellows in lateral and axial directions were realised by a test rack. The design of this test rack had to meet the requirement of parallel movement of both flanges (up and down side of the bellows) during lateral strokes. Four special struts, two per side, were fixed on the test rack. A lubricated bearing was positioned on each end of the struts (figure 5).

The test programme was fixed within a technical specification [4]. The measurements were performed on a three axis CNC machine and monitored in a stroke-force diagram.

The strokes were performed by a special tool of the CNC machine. A load cell was located within the connection from the machine to the test apparatus. 


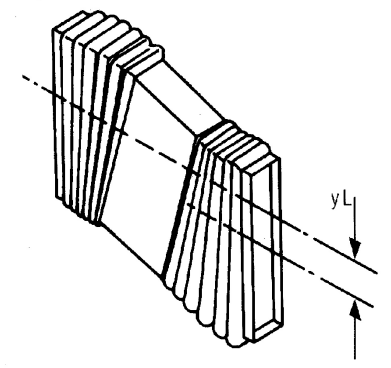

Fig 3. Rectangular bellows, movements over long side

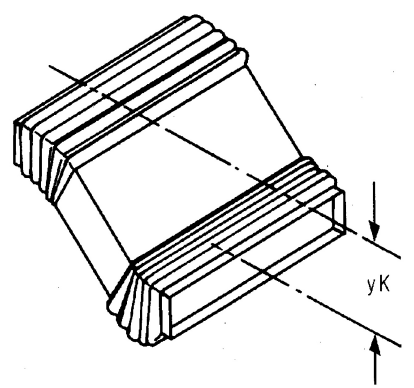

Fig. 4. Rectangular bellows, movements over short side

In figure 5 the principle of the described test rack is to be seen. Figure 6 shows the rectangular bellows fixed in the test rack on a three axis machine during the lateral test series. The movements over the long side result in deformation of the bellows.

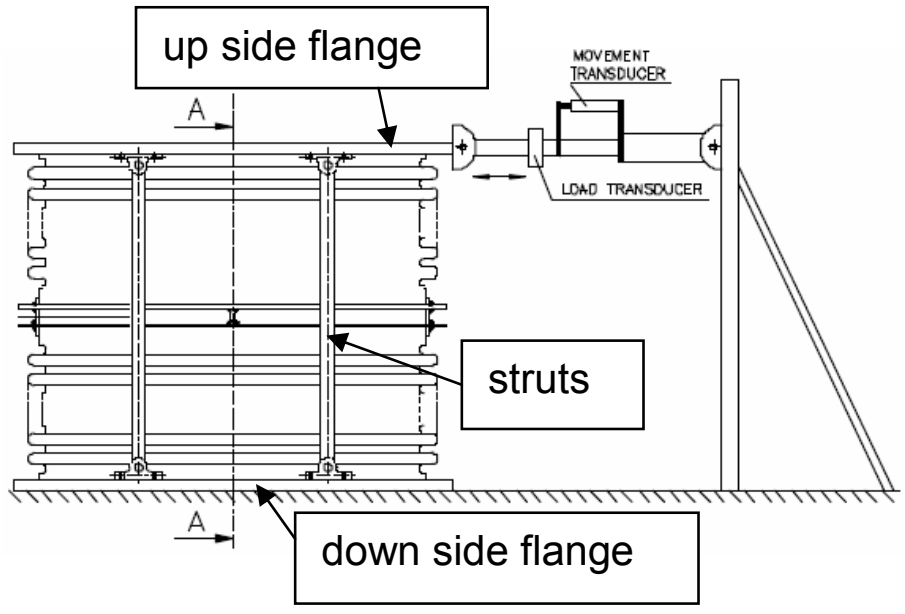

Fig. 5. Principle of test rack with struts

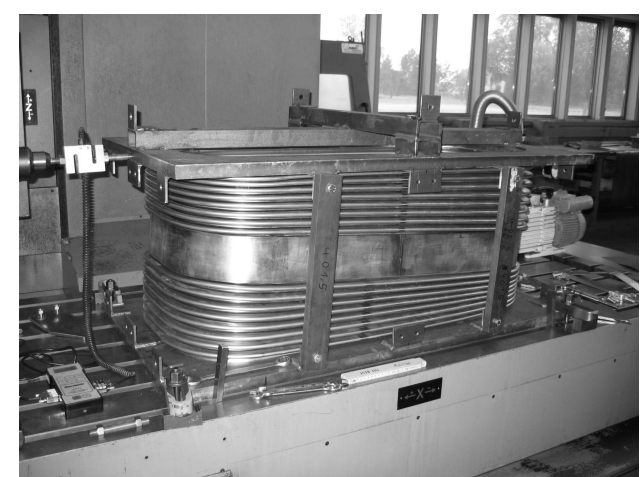

Fig. 6. Rectangular bellows during lateral movements 


\section{Test procedures for rectangular bellows}

In order to check the behaviour of the bellows on intermediate points the maximum strokes of the bellows were divided into several steps (table 2). To overcome the hysteresis effect the bellows were cycled tree times on each intermediate point.

\begin{tabular}{|c|c|c|c|}
\hline Step & $\begin{array}{c}\text { Axial movement } \\
\text { test } \\
(\mathrm{mm})\end{array}$ & $\begin{array}{c}\text { Lateral movement } \\
\text { test } \\
\text { (long side) } \\
(\mathrm{mm})\end{array}$ & $\begin{array}{c}\text { Lateral movement } \\
\text { test } \\
\text { (short side) } \\
(\mathrm{mm})\end{array}$ \\
\hline & 10 & 5 & \\
1 & 20 & 10 & 15 \\
2 & 30 & 15 & 20 \\
3 & 37 & & 24 \\
4 & & & 15 \\
\hline
\end{tabular}

Table 2. Strokes to reach the maximum movement in each direction

All ports and their bellows work at $60^{\circ} \mathrm{C}$ to $80^{\circ} \mathrm{C}$ during normal load cases and up to $150^{\circ} \mathrm{C}$ during heating.

Since these temperatures are expected to have little influence on the spring-rates during the test it was decided to use room temperature as reference temperature.

On the other hand the influence of the interspace vacuum inside the bellows was not known. Therefore each stroke was performed twice, first under normal air pressure, second under vacuum $\left(<1^{*} 10^{-3} \mathrm{mbar}\right)$. 


\section{Results of the tested rectangular bellows}

Table 3 shows the summarised results of the measurements in axial, long-side lateral and short-side lateral direction.

\begin{tabular}{|c|c|c|c|c|c|c|c|c|}
\hline Step & \multicolumn{2}{c|}{$\begin{array}{c}\text { Axial } \\
\text { compressed }\end{array}$} & \multicolumn{2}{c|}{$\begin{array}{c}\text { Axial } \\
\text { stretched }\end{array}$} & \multicolumn{2}{c|}{$\begin{array}{c}\text { Lateral } \\
\text { Long side }\end{array}$} & \multicolumn{2}{c|}{$\begin{array}{c}\text { Lateral } \\
\text { Short side }\end{array}$} \\
\hline & \multicolumn{2}{|c|}{$\mathrm{N} / \mathrm{mm}$} & \multicolumn{2}{c|}{$\mathrm{N} / \mathrm{mm}$} & \multicolumn{2}{c|}{$\mathrm{N} / \mathrm{mm}$} & \multicolumn{2}{c|}{$\mathrm{N} / \mathrm{mm}$} \\
\hline 1 & 67 & 74 & 68 & 74 & 369 & 392 & 154 & 162 \\
\hline 2 & 67 & 73 & 67 & 69 & 371 & 392 & 161 & 168 \\
\hline 3 & 66 & 70 & 68 & 69 & 365 & 407 & 166 & 172 \\
\hline 4 & 66 & 69 & 68 & 69 & 389 & 417 & & \\
\hline$\varnothing$ & 67 & 71 & $\mathbf{6 8}$ & 70 & $\mathbf{3 7 4}$ & $\mathbf{4 0 2}$ & $\mathbf{1 6 0}$ & 167 \\
\hline $\begin{array}{c}\text { FEM } \\
\text { results }\end{array}$ & & & $\mathbf{6 3}$ & & $\mathbf{4 7 4}$ & & $\mathbf{1 4 7}$ & \\
\hline $\begin{array}{c}\text { EJMA } \\
\text { code }\end{array}$ & 59 & & $\mathbf{5 9}$ & & $\mathbf{1 9 3}$ & & $\mathbf{4 2}$ & \\
\hline
\end{tabular}

Table 3. Results of the test series [5]

Three main results as the outcome of this test series can be stated:

I. The influence of the interspace vacuum between the layers of the bellows is minimal.

II. The axial spring rates met those calculated from the EJMA code.

III. The lateral spring rates had deviations up to $250 \%$ to the EJMA code values, confirming the FEM analysis results

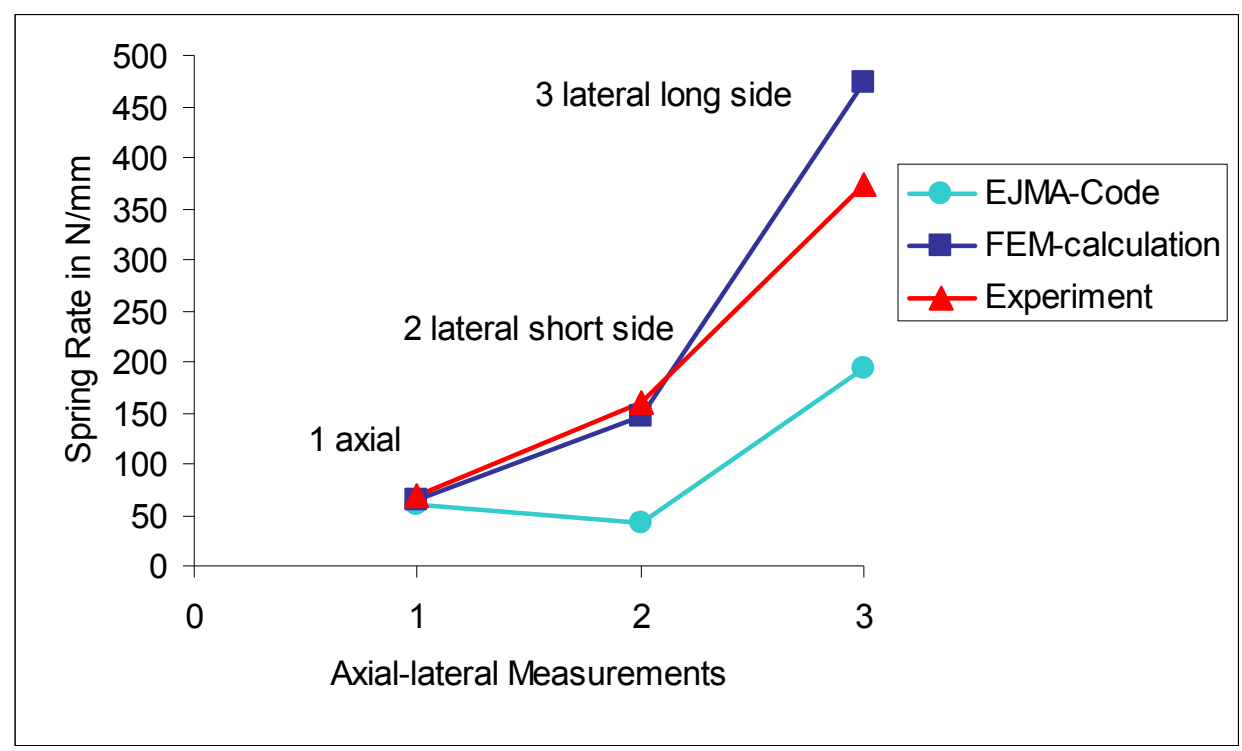

Fig. 7. Comparison of spring-rate values (EJMA, FEM and Experiment) 
The lateral spring rate values of the FEM calculation were confirmed. They are significantly higher then the calculated spring rates of the EJMA code.

\section{Conclusions}

It was shown by the test campaign that high deviations occurred between the given values of the spring-rates of multilayer rectangular bellows from the EJMA code and the values from tests.

All oval and rectangular bellows were re-checked separately. The spring rate values resulted from these tests were used as reference values to correct the global FEM model which will be used by IPP for the calculation of the W7-X machine. The reference values were also taken for the design of the support system of the vessels.

The EJMA code should be modified for oval and rectangular bellows as those tested. Additional data should be collected for bellows shapes which deviate from standard. 
References:

[1] EJMA code, Standards of the expansion joint manufactures association, INC. 25 North Broadway, Tarrytown, NY 10591

[2] J. Reich, et al, Manufacture of the vacuum vessels and the ports of Wendelstein 7-X, Fusion Eng. Des. 75-79 (2005) 565-569

[3] A. Capriccioli, Connections between plasma and outer vessel ports: Bellows FE models 1-YBA-T0000.0, IPP doc., 28.11.2005

[4] Idrosapiens S.r.I., Experimental determination of the spring rates on multilayer rectangular bellows, Technical specification 1-AE-S0012.1, IPP doc., 05.07.2005

[5] Kompaflex AG., Experimentelle Ermittlung der Rechteckbalg-Federraten, Zusammenfassung der Testergebnisse 1-AE-T2019.0, IPP doc., 26.09.2005 